\title{
Investigation of fuel reduction potential of a capacity controlled HVAC system for buses using virtual test drives
}

\author{
Christian Kaiser ${ }^{1} \quad$ Sebastian Meise $^{2} \quad$ Wilhelm Tegethoff ${ }^{1} \quad$ Jürgen Köhler $^{2}$ \\ ${ }^{1}$ TLK-Thermo GmbH, Germany, \{c.kaiser, w.tegethoff $\}$ atlk-thermo.com \\ ${ }^{2}$ Institut für Thermodynamik, TU-Braunschweig, Germany, $\{$ s.meise, juergen.koehler\}@tu-braunschweig.de
}

\begin{abstract}
The refrigerant cycle in conventional omnibus HVAC systems has a significant influence on fuel consumption and, as a result, on vehicle emissions. The additional emissions resulting from the use of the air conditioning system are called indirect emissions. In addition, there are so-called direct emissions from the air conditioning system caused by unintended leakage of refrigerant. A reduction in indirect emissions can be achieved, for instance, by adjusting the capacity of the refrigerant compressor. A reduction in direct emissions can be achieved by so-called alternative or natural refrigerants. To investigate approaches to reducing direct and indirect emissions, a total vehicle simulation model of a coach with detailed HVAC systems was developed with full implementation in Modelica. For this total vehicle simulation of a coach with a detailed HVAC system, a refrigerant cycle based on the natural refrigerant $\mathrm{CO}_{2}$ (R-744) was modeled and validated. In addition, an efficient control strategy was developed by adjusting the capacity of the refrigerant compressor to cover the actual cooling capacity demand and save fuel. Based on virtual driving test scenarios, the fuel saving potential of the developed compressor capacity control strategy is investigated to determine average annual fuel savings.
\end{abstract}

Keywords: HVAC, MAC, Energy efficiency, Omnibus, Total vehicle simulation, Virtual test drive, R-744, Fuel saving, Compressor capacity control, Cooling capacity control, Thermal systems

\section{Introduction}

Reciprocating compressors with constant displacement are typically used in air conditioning systems for conventional buses. The compressor is usually driven directly by the internal combustion engine through the use of a belt drive and a magnetic clutch. Due to the speed-synchronous mechanical linkage to the engine and the constant compressor displacement, different control techniques and methods are needed to realize variable cooling capacity based on compressor capacity control for efficient use of the air conditioning system. For this purpose, a combination of speed control by means of a two-speed pulley gearbox based on a planetary gearbox and cylinder bank shutdown by suction gas interlock are developed. In addition, there are other techniques and methods to adapt the refrigerant compressor capacity for cooling capacity control of reciprocating compressors with constant displacement (see Kaiser, 2018): for instance, refrigerant compressor capacity control by cycling clutch operation with a magnetic clutch or compressor speed control by continuously variable transmission or by separate drive with an electric machine as well as the use of semi-hermetic electric compressors. The cycling clutch operation of the magnetic clutch causes uncomfortable fluctuations in the interior temperature. The compressor speed control by continuously variable transmission is complex and requires lot of installation space. The use of a separate electric machine or semi-

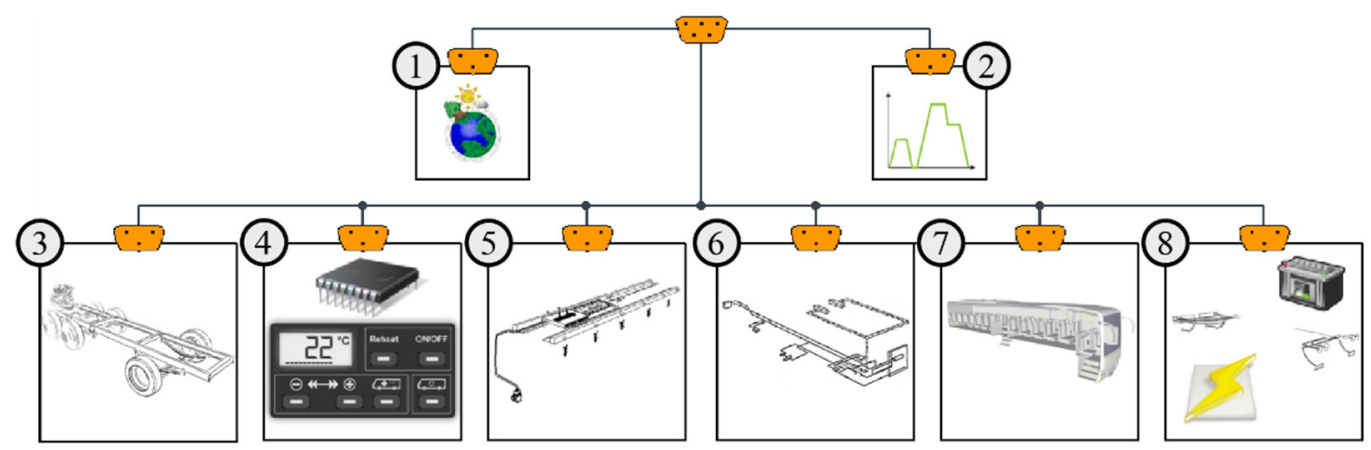

Figure 1. Modelica-based total vehicle simulation model of a coach: (1) Ambient conditions, (2) Driving conditions,

(3) Vehicle longitudinal dynamics, (4) HVAC controller, (5) Refrigerant cycle, (6) Engine cooling and interior heating cycle, (7) Vehicle cabin and (8) Electrical system. 


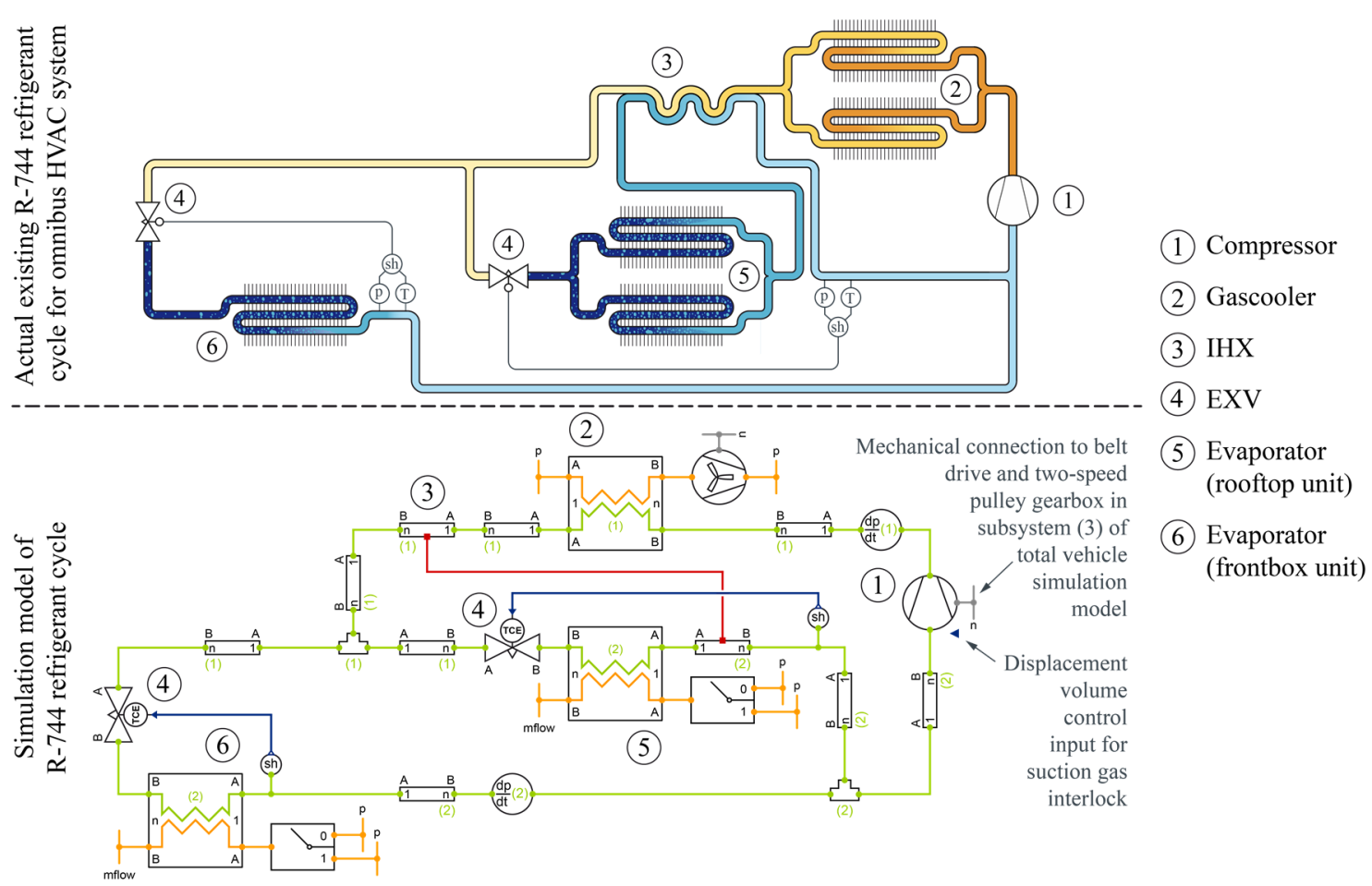

Figure 2. Structure of actual existing R-744 refrigerant cycle for omnibus HVAC system and topology of the corresponding R-744 refrigerant cycle simulation model based on (TIL Suite, 2018)

hermetic electric compressor requires lot of installation space as well. Generally, installation of electric driven compressors is more expensive than open-type mechanical compressors because of the additional need for more or more powerful electric generators and for a frequency converter for compressor speed adaption. Compared to a conventional mechanically driven compressor, the conversion from mechanical to electrical energy and back to mechanical energy for electric driven compressors leads to additional energy losses. Nevertheless, omnibus HVAC systems based on electrically driven compressors are currently being investigated, see (Meise et al, 2018; Hebeler et al, 2018). In contrast to the above-mentioned compressor capacity control techniques and methods, the combination of two-speed pulley gearbox and cylinder bank shutdown is not complex, requires nearly no further installation space and entails no additional energy losses through energy conversion. For this reason, the combination of two-speed pulley gearbox and cylinder bank shutdown is the best solution for use in conventional buses.

The study of this combination of two-speed pulley gearbox and cylinder bank shutdown is done by means of a detailed vehicle simulation of a coach. The vehicle model of a coach was developed and validated for research issues in the realm of air conditioning systems in buses, see (Kaiser, 2018). Figure 1 shows the overall model, which includes the following subsystems: ambient and driving conditions as boundary conditions, longitudinal driving dynamics, climate controller, refrigeration cycle, engine cooling and heating cycle, interior of the bus as well as the electrical system.
Special emphasis was put on detailed models with modeling of all fundamentally relevant heat transfers and pressure losses for two air conditioning systems based on refrigerant R-134a and R-744. A detailed description of modeling the R-744 refrigerant cycle appears below. Further on, the two-speed pulley gearbox based on a planetary gearbox and the cylinder bank shutdown by suction gas interlock are described briefly. After that, two climatically different driving route scenarios for the comparative study are introduced. To conclude, the numerical simulation results of the specified compressor capacity control method are presented depending on two driving route scenarios (Germany, Portugal/Spain).

\section{Modeling of R-744 refrigerant cycle for coach HVAC system}

The following section presents the structure of an actual existing R-744 refrigerant cycle for an omnibus HVAC system as well as the topology of the corresponding simulation model. Subsequently, the modeling of the R-744 refrigerant cycle based on selected heat transfer and pressure drop correlations is described and the results of the calibration and validation process are shown.

\subsection{Modeling of R-744 refrigerant cycle}

Figure 2 shows the structure of an actual existing R-744 refrigerant cycle for an omnibus HVAC system and the corresponding simulation model of the R-744 refrigerant cycle. The side-by-side illustration of the refrigerant cycle structures shows that the parallel heat 
exchangers (gascooler and evaporator) of the rooftop unit are merged in one corresponding heat exchanger model in the R-744 refrigerant cycle model. In this merging process, the geometric, all thermal and hydraulic characteristics of the parallel heat exchangers are accounted for in the corresponding single heat exchanger models. For modeling of the R-744 refrigerant cycle, off-the-shelf models from the Modelica library (TIL Suite, 2018) were used (Richter, 2008; Gräber et al, 2010; Tegethoff et al, 2011, Schulze, 2013). The heat exchanger models of the gascooler and evaporator are modeled according to the finite volume method with 10 discrete volumes each. The IHX (internal heat exchanger) is also modeled according to the finite volume method, but with 4 discrete volumes. All of them used models from the Modelica library (TIL Suite, 2018) with a stream operator and all of them allow for reversal of flow and zero mass flow, see (Schulze, 2013. The models used are very robust and well suited for high dynamic simulation applications with VLE (vapor-liquid equilibrium) fluids, e.g. HVAC systems. The R-744 refrigerant cycle model shown in Figure 2 has 391 continuous time states and 19740 timevarying variables. The translated model of the R-744 refrigerant cycle has 2 linear equations, where the linear equation system size is 2 and 3. In addition, the translated model has 20 nonlinear equations, where each nonlinear equation system has size 1 . Model translation and manipulation was done using Dymola.

The following describes the selected correlations for calculating thermal and hydraulic characteristics of the R-744 refrigerant cycle. Basically, all thermal and hydraulic calculations in all component models in the R-744 simulation model are based on geometric parameters of the existing R-744 refrigerant cycle. For the air side of all heat exchangers, the calculation of convective heat transfer and pressure drop is based on the calculation published by (Haaf, 1988). On the refrigerant side of the heat exchangers, the refrigerant undergoes phase change processes. For this purpose, specific correlations are implemented. For the singlephase refrigerant in laminar flow region $(\operatorname{Re}<2300)$, the heat transfer coefficient is determined using the constant Nusselt number of $\mathrm{Nu}=3,657$. For the single-phase refrigerant in turbulent flow region of $2300<\mathrm{Re}<10^{4}$, the correlation of (Gnielinski, 1975) and, for larger Reynolds Numbers $\left(\operatorname{Re}>10^{4}\right)$, the correlation of (Dittus and Boelter, 1930) is used to calculate the Nusselt number. If the high-pressure-side heat exchanger (gascooler) operates supercritically, the refrigerant-side heat transfer in the range of $2300<\operatorname{Re}<10^{4}$ is calculated with the correlation of (Gnielinski, 1975), which is also used in the subcritical region, and single phase flow for the same range of the Reynolds number. If the high-pressure-side heat exchanger operates subcritically and the refrigerant passes the phase change process, the heat transfer is calculated with the correlation of (Cavallini et al, 2006). Additionally, for improving the correlation of (Cavallini et al, 2006) the approach of (Fujii and Watabe, 1987) was integrated as shown by (Kondou and Hrnjak, 2011). The heat transfer in the evaporators during the evaporation phase changing process is calculated with the correlation of (Gungor and Winterton, 1987).

Predicting hydraulic losses in the heat exchangers is complex during the phase change process. Two basic calculation methods for determining hydraulic losses in two-phase flow are shown, for instance, by (Wallis, 1969) and (Rohsenow et al, 1985). On one hand, the homogeneous calculation method applies, which assumes equal velocities for the liquid and vapor phase. On the other hand, the heterogeneous calculation method applies, in which the liquid and vapor phase have different flow velocities, so that slippage between the two phases can be considered. For calculations of hydraulic losses in the R-744 refrigerant cycle model, the homogeneous calculation method is used. According to the assumption of equal velocities of the liquid and vapor phase, the average density is calculated based on the vapor content of the assumed homogeneous flow (Baehr and Stephan, 2006). In addition, the dynamic viscosity of the assumed homogeneous flow is determined by the approach of (McAdams et al, 1942). The final calculation of the pressure drop in the two-phase flow is calculated by the explicitly formulated approximation of the Colebrook-White equation of (Swamee and Jain, 1976). The pressure drop in all refrigerant pipes and the turbulent flow region

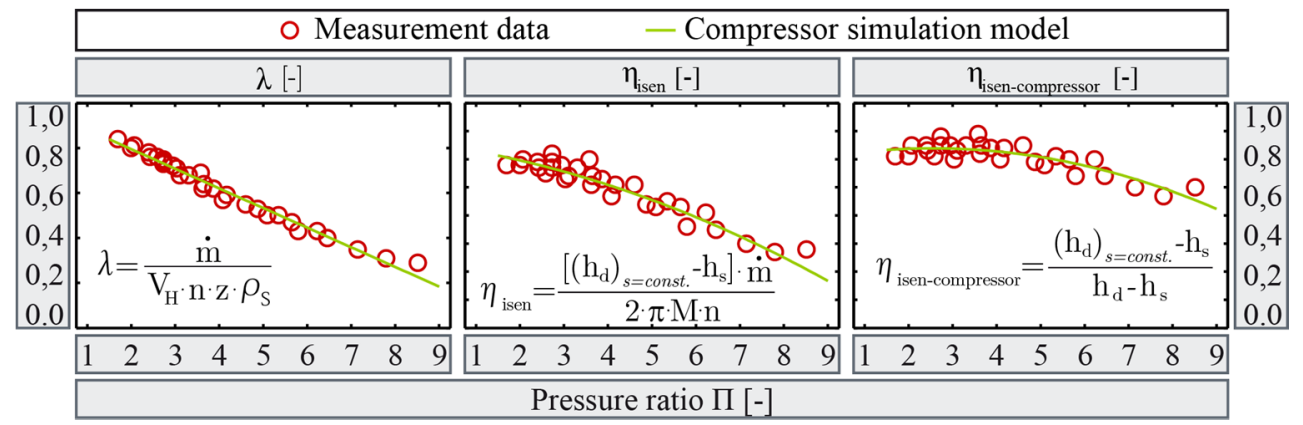

Figure 3. Comparison of implemented compressor model functions (green curves) for volumetric efficiency $\lambda$, isentropic efficiency $\eta_{\text {isen }}$ and isentropic compressor efficiency $\eta_{\text {isen-Compressor }}$ with measured data based points (red circles) at a constant compressor speed of $\mathrm{n}=1000 \mathrm{~min}^{-1}$ (measurement data and equation definition based on (Försterling, 2003)). 


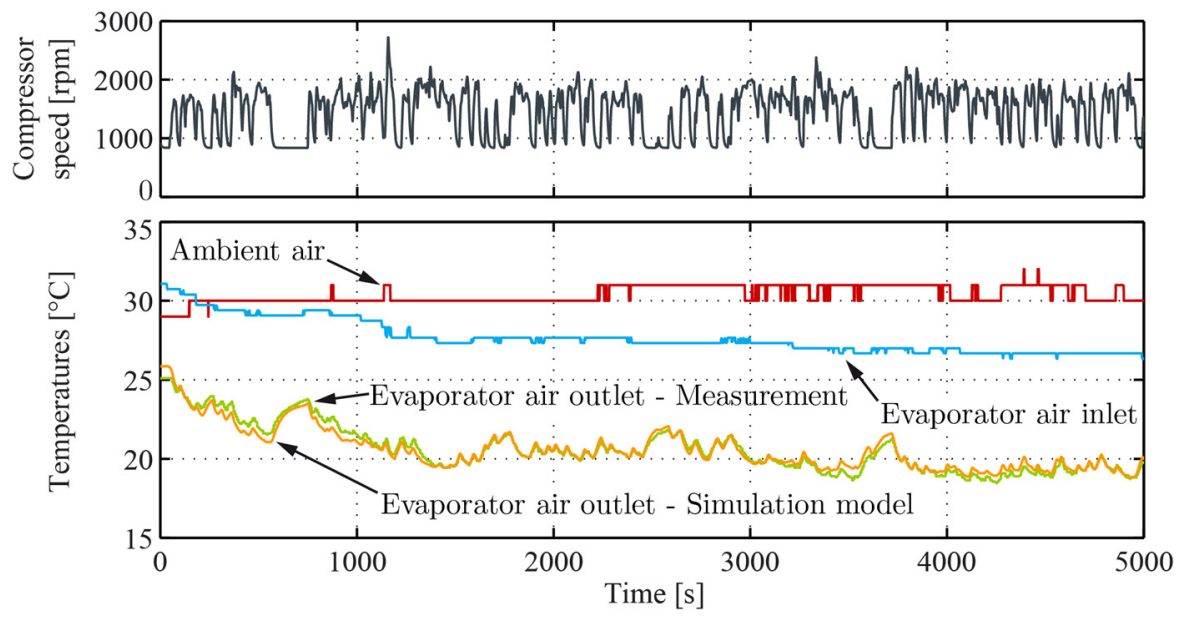

Figure 4. Top: compressor speed of simulation model based on measured engine speed. Bottom: measured ambient air temperature and measured air temperature at rooftop evaporator inlet (also used as evaporator inlet air temperature in simulation model) as well as comparison of measured and simulated air temperature at rooftop evaporator outlet.

$(\mathrm{Re}>2300)$ is calculated using the formulation of (Swamee and Jain, 1976) as well. In the laminar flow region $(\operatorname{Re}<2300)$, the pressure drop in all refrigerant pipes is calculated with $\zeta=64 / \mathrm{Re}$.

For modeling the compressor model, (TIL Suite, 2018) offers two basic modeling approaches: an efficiency-based compressor model and a physicalbased compressor model. The compressor model used for the R-744 refrigerant cycle model follows the efficiency-based approach, as shown by (Försterling, 2003). Therefore, the compressor model is characterized by a volumetric efficiency $\lambda$, an isentropic efficiency $\eta_{\text {isen }}$ and an isentropic compressor efficiency $\eta_{\text {isen- }}$ Compressor. Figure 3 shows a comparison of the implemented model functions for the volumetric efficiency $\lambda$, isentropic efficiency $\eta_{\text {isen }}$ and isentropic compressor efficiency $\eta_{\text {isen-Compressor }}$ with data points based on measurement data.

\subsection{R-744 simulation model validation results}

The previously described simulation model of the R-744 refrigerant cycle is calibrated and validated with measurement data of a vehicle measurement campaign. The following validation shows a section of this measurement campaign for a summer afternoon with an average ambient temperature of approximately $30^{\circ} \mathrm{C}$.

For the calibration of the R-744 refrigerant cycle model, the previously specified heat transfer and pressure drop calculation at the refrigerant side were adapted with the aid of a constant calibration factor for each heat transfer and pressure drop calculation. As a result, the heat transfer and the pressure drop calculation at the gascooler, the IHX, the frontbox evaporator and rooftop evaporator were adapted based on constant calibration factors. At the refrigerant pipes, only the pressure drop calculation was adapted based on constant calibration factors in each pipe. Model calibration was performed using the complete closed refrigerant cycle model as presented in Figure 2, where measured data were used as input values e.g. for the air temperature at the gascooler and both evaporator inlets as well as for compressor speed. For the model calibration, the deviation of the simulated refrigerant temperatures and pressures from measured refrigerant temperatures and pressures as well as the simulated and measured air

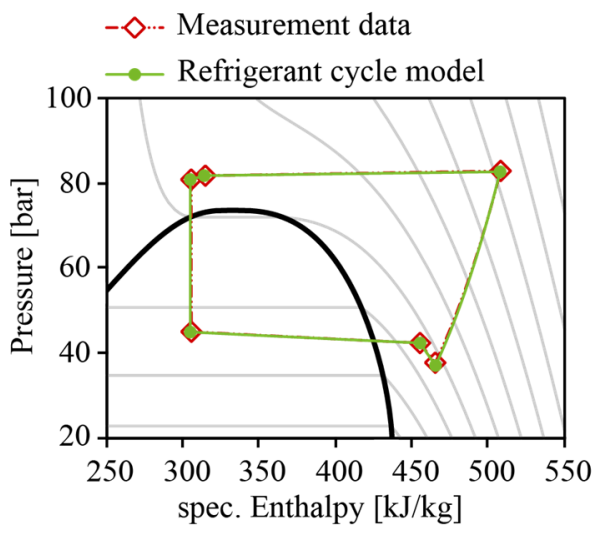

Figure 5. Comparison of calibration results of the R-744 refrigerant cycle model with measured data in ph-state diagram at $\mathrm{t}=2000 \mathrm{~s}$.

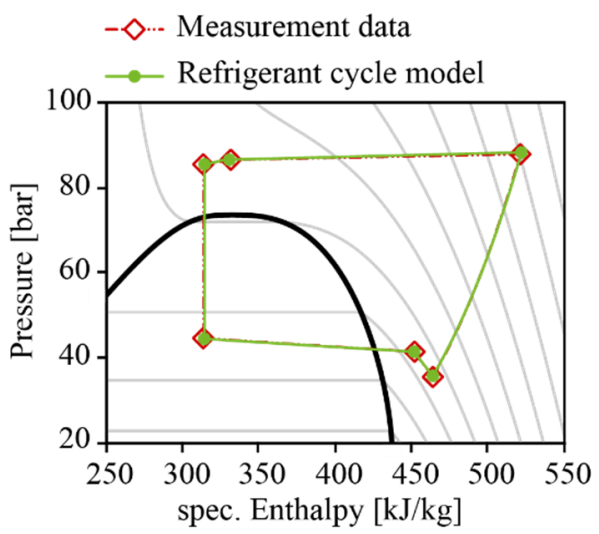

Figure 6. Comparison of calibration results of the R-744 refrigerant cycle model with measured data in ph-state diagram at $\mathrm{t}=3500 \mathrm{~s}$. 
temperatures at the outlet of the gascooler and evaporators were minimized using the method of the smallest error squares. The calculation of the airsideheat transfer and pressure drop were not modified.

The validation results of the calibrated R-744 refrigerant cycle model are shown in Figure 4, Figure 5 and Figure 6. Figure 4 shows the comparison of the measured and simulated air temperature at the outlet of the rooftop evaporator. The curves of the measured and simulated air temperatures fit together very well. The state diagrams in Figure 5 and Figure 6 show the refrigerant-side process compared to measured data at different times of the validation comparison (cf. Figure 4). This comparison of the simulated and measured process states shows a good matching. Therefore it can be said that the specific heat of the gascooler, evaporator and IHX as well as the refrigerant outlet temperature and pressure ratio of the compressor are simulated correctly. Finally, the modeled R-744 refrigerant cycle model shows a very good match to measured data.

Based on the very dynamic measurement data (as shown in Figure 4), the CPU time for integration of the R-744 refrigerant cycle model was more than 8 times faster than real time. To determine the CPU time, the R-744 refrigerant cycle model was simulated on a standard laptop.

\section{Compressor capacity control method}

The following section introduces and specifies an innovative method for implementing capacity adaptation in the refrigerant compressor of omnibus air conditioning systems. This innovative method consists, on one hand, of a compressor speed control by means of a two-speed pulley gearbox based on a planetary gearbox and, on the other hand, on a cylinder bank shutdown by suction gas interlock. The pulley gearbox based on a planetary gearbox is integrated in the compressor belt pulley, which was presented for automotive application by (Baumgart et al., 2006). With this integrated planetary gearbox, two transmission ratios $(i<1$ and $i=1)$ can be implemented. Figure 7 shows the design, schematic and operating principle of the pulley gearbox. Insofar as the brake is closed and the clutch is released (switch position $\mathrm{I}$, $\mathrm{n}_{\text {Planet carrier }}=0$ ), the gearing between the ring gear and the sun gear generates a transmission ratio into higher speed $(i<1)$. If the brake is released and the clutch is closed, the gear unit rotates as one part (switch position II, $\mathrm{n}_{\text {Planet carrier }}=\mathrm{n}_{\text {Sun gear, }}, \mathrm{i}=1$ ) and the gearbox runs without any friction losses. In this case, the refrigerant compressor is driven only by the transmission ratio of the belt drive. If both the brake and the clutch are released, the planetary gearbox is underdetermined and decouples the refrigerant compressor from the belt drive (switch position III), thus enabling the refrigerant compressor to be disconnected from the drive as before with a conventional magnetic clutch. The simulation model of the two-speed pulley gearbox converts the speed of the belt drive connected to the internal combustion engine (in subsystem 3, see Figure 1) to the compressor (in subsystem 5, see Figure 1) of the refrigerant cycle model presented in Figure 2. A control signal to the gearbox model activates or deactivates the speed conversion in the gearbox based on described switch positions and the Willis equation shown in Figure 7.

The cylinder bank shutdown by suction gas interlock is usually installed in the cylinder head of one cylinder or cylinder pair of the refrigerant compressor. Figure 8 illustrates the schematic and operating principle of the suction gas interlock. Insofar as no voltage is applied to the solenoid valve, the high pressure pass to the locking valve is closed and the spring pushes the locking valve into the upper valve seat. The connection between the suction chamber and suction gas line is open, and the refrigerant compressor operates at full capacity. When the solenoid valve is actuated, the access of the high pressure pass to the locking valve is opened, high pressure refrigerant flows above the locking valve and presses it into the lower valve seat. As a result, the connection between the suction chamber and suction gas line is blocked and the refrigerant compressor operates at reduced capacity. In the simulation model, the suction gas interlock is implemented by modifying the effective displacement volume $\left(\mathrm{V}_{\mathrm{H}} \mathrm{z}\right)$ of the

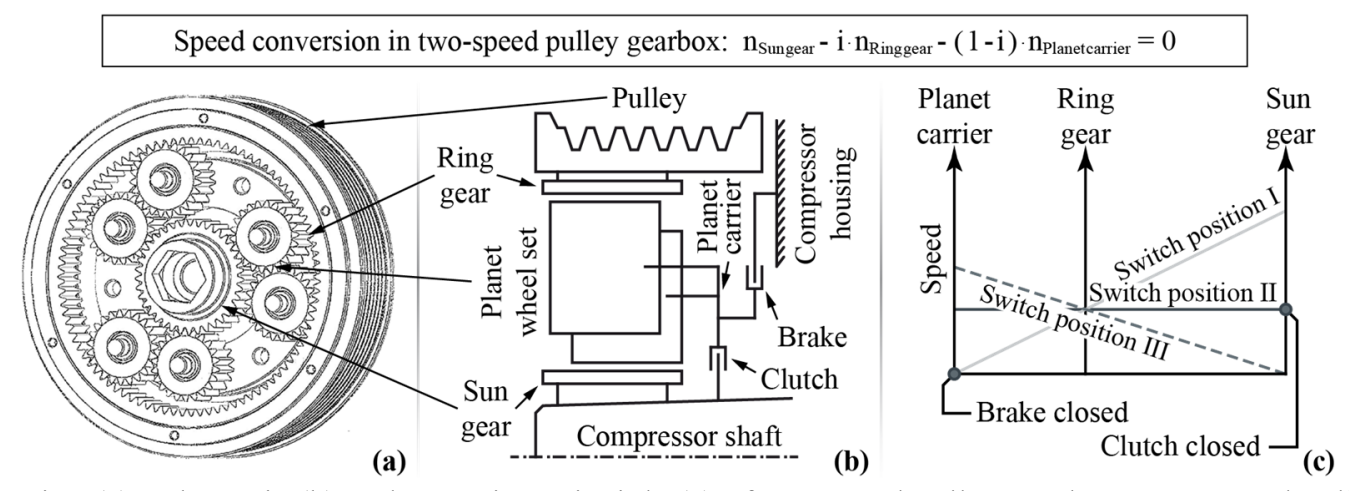

Figure 7. Design (a), schematic (b) and operating principle (c) of two-speed pulley gearbox. Two-speed pulley gearbox converts speed of the belt drive to refrigerant compressor shaft based on Willis equation above. 

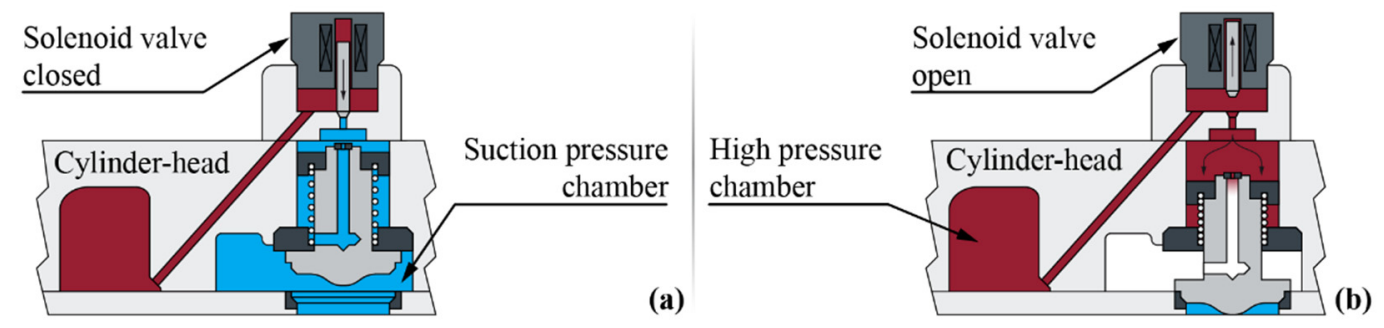

Figure 8. Schematic and operation principle of suction gas interlock: (a) inactive interlock, (b) active interlock. The suction gas interlock is integrated in the cylinder-head of a cylinder pair and locks the connection to the suction gas line.

refrigerant compressor model, see Figure 2. Because of this, volumetric efficiency and, as a result, isentropic and isentropic compressor efficiency are also affected, see equations in Figure 3.

Table 1. Transmission ratios for refrigerant compressor drive by two-speed pulley gearbox.

\begin{tabular}{|c|c|}
\hline Switch position & Transmission ratio $i$ \\
\hline I & 0.654 \\
\hline II & 1.0 \\
\hline
\end{tabular}

For the study within the vehicle simulation, Table 1 shows the selected transmission ratios for the refrigerant compressor drive with the two-speed pulley gearbox application. For the selection of the compressor drive, total transmission ratios of the belt drive and planetary gearbox, the conventional belt drive transmission ratio should be maintained. Selection of the second additional transmission ratio is based on a preliminary study (Kaiser et al., 2013). This second additional transmission ratio was selected in such a way that frequent shift operations of the two-speed pulley gearbox and activation of the suction gas interlock during normal operational speed changes of the internal combustion engine can be avoided in general driving mode. This is also intended to keep the superheat control from oscillating.

To adapt the refrigerant compressor speed, the twospeed pulley gearbox is controlled depending on the interior temperature (reflects the actual cooling demand). If the interior temperature reaches or exceeds the upper value of $t_{S e t}+0.5 \mathrm{~K}$, where $t_{\text {Set }}$ is the interior set temperature, the two-speed pulley gearbox shifts into switch position I. If the interior temperature reaches or falls below the lower value $t_{S e t}$, the two-speed pulley gearbox shifts into switch position II. Friction power losses with an active two-speed pulley gearbox in switch position I are calculated with a gear box efficiency of $\eta=0.96$ according to (Baumgart, 2010).

To adapt the refrigerant compressor capacity based on the cylinder bank shutdown, the suction gas interlock is controlled depending on the interior temperature as well. If the interior temperature reaches or falls below the lower value $t_{s e t}$, where $t_{s e t}$ is the interior set temperature, the suction gas interlock application is activated. If the interior temperature reaches or exceeds the upper value of $t_{\mathrm{Set}}+0.5 \mathrm{~K}$, the suction gas interlock application is deactivated. Based on the cylinder bank shutdown by suction gas interlock, the refrigerant compressor displacement volume can be controlled between $50 \%$ and $100 \%$.

For the study within the vehicle simulation, the refrigerant compressor capacity control by means of the two-speed pulley gearbox application and the suction gas interlock application are used as follows: First, the refrigerant compressor speed is adapted by the two-speed pulley gearbox. Afterwards, the two-speed pulley gearbox is in switch position II, and the cylinder bank shutdown by suction gas interlock can be activated.

\section{Virtual driving route test scenarios}

Two climatically different driving scenarios were realistically modeled for the addressed research issues in the realm of bus air conditioning systems. For this, Figure 9 shows the selected driving routes in their respective map sections, which are dynamically driven through with the total vehicle model shown in Figure 1. Based on the geographic coordinates of these two driving scenarios, individual velocity and elevation profiles were calculated to describe the target state for the vehicle model driving simulation. Depending on the defined velocity profile and the geographic position, time-dependent representative ambient conditions were calculated based on a meteorological database (METEONORM, 2016; Remund et al., 2013) for the two driving route scenarios. For the presentation of an annual cross-section, transient ambient conditions are calculated for every $15^{\text {th }}$ of the month in a representative year. Thus the ambient conditions include ambient air temperature, ambient air pressure, ambient relative humidity as well as direct and diffuse ambient solar radiation. Figure 9 shows the calculated ambient air temperature curves for the two driving route scenarios as an example. The numbered ambient air temperature curves represent the $15^{\text {th }}$ of each numbered month. The background areas in gray represent the ambient temperature range in which the refrigerant circuit is not active with respect to the climate controller algorithms implemented. In this process, the refrigerant circuit is automatically switched off at $\mathrm{t}_{\mathrm{amb}} \leq 13^{\circ} \mathrm{C}$ and automatically switched on at $t_{a m b} \geq 15^{\circ} \mathrm{C}$. 

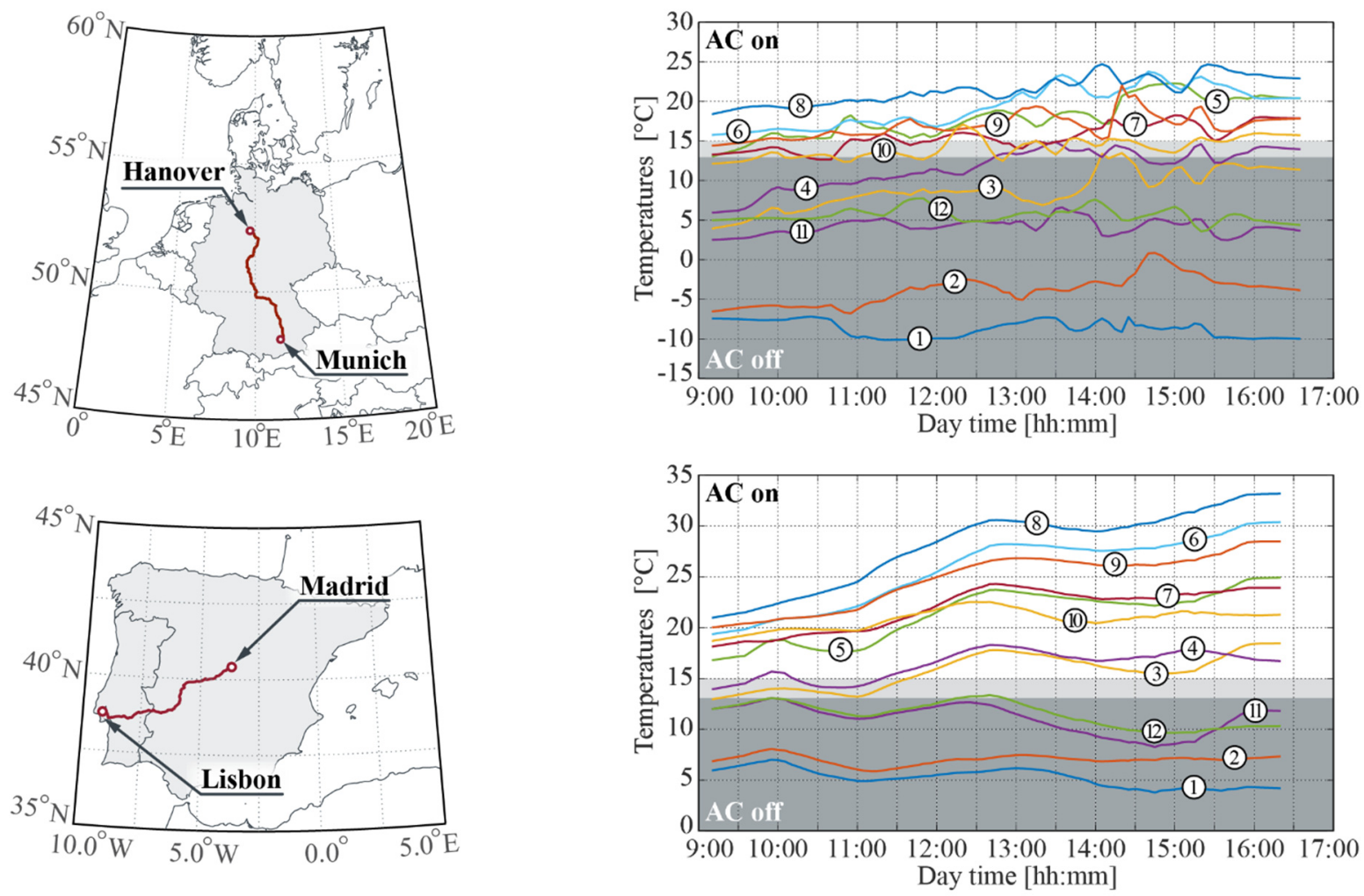

Figure 9. Realistically modeled driving route scenarios and corresponding transient ambient temperatures for every $15^{\text {th }}$ of the month in a representative year based on a meteorological database. Driving route scenarios: Hanover to Munich (top),

Lisbon to Madrid (bottom), numbered temperature curves: (1) represents $15^{\text {th }}$ of January ... (12) represents $15^{\text {th }}$ of

December; gray temperature areas: $t_{\mathrm{amb}} \leq 13^{\circ} \mathrm{C}$ refrigerant cycle is off, $\mathrm{t}_{\mathrm{amb}} \geq 15^{\circ} \mathrm{C}$ refrigerant cycle is on.

\section{Results}

This section presents the numerical results of the total vehicle simulation with application of the refrigerant compressor capacity control method described above.

Figure 11 shows the dynamic simulation results of the total vehicle simulation with the R-744 refrigerant cycle for the virtual test driving route scenario from Lisbon to Madrid on a representative $15^{\text {th }}$ of August. It shows the ambient boundary conditions including ambient air temperature, ambient air pressure, ambient relative humidity as well as direct and diffuse ambient solar radiation. It also shows the average interior

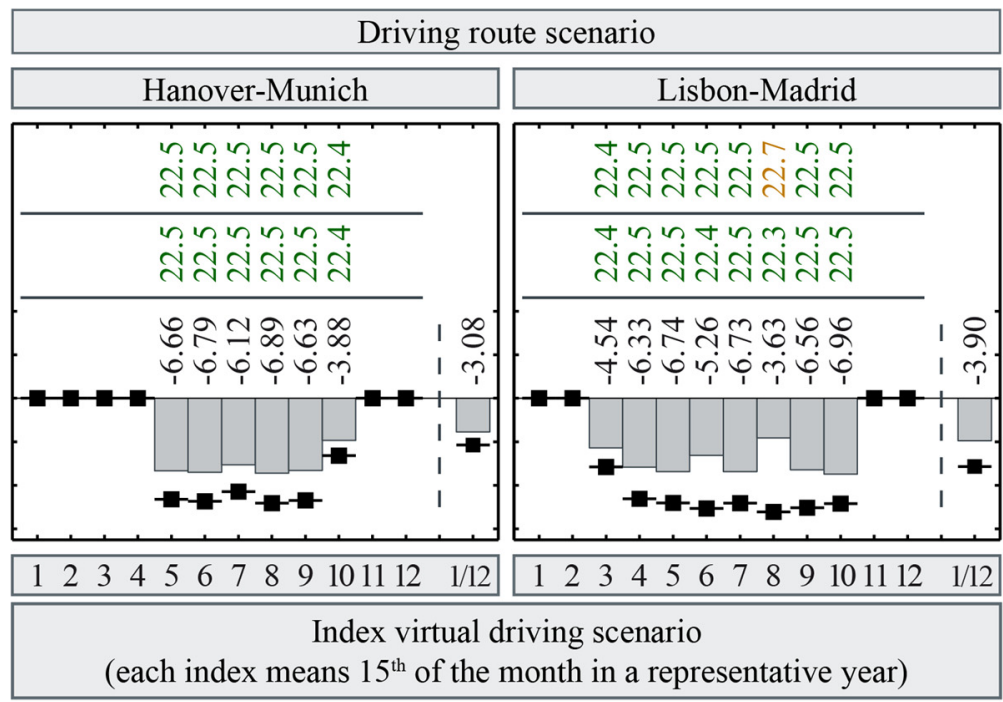

Figure 10. Numerical results of application combination of two-speed pulley gearbox and suction gas interlock for R-744-based air conditioning system. Shows the fuel consumption of each monthly driving scenario and, in the last column of each diagram, the average annual fuel consumption (1/12). Black boxes present the theoretical limit potential of fuel savings through operation of the air conditioning system. Set temperature for interior air temperature control in driver's workspace and passenger compartment is $t_{S e t}=22.5^{\circ} \mathrm{C}$. 
temperature as well as the control behavior of the two-speed pulley gearbox and the suction gas interlock. Additionally it presents the refrigerant compressor speed and the compressor outlet refrigerant mass flow rate.

To evaluate the efficiency of the developed and investigated compressor capacity control method, vehicle fuel consumption is used for valuation purposes. This is done because vehicle fuel consumption includes all multivariable dependencies of the total vehicle model and of the investigated compressor capacity control methods and their sensitivities to the total vehicle simulation model. The results of the change in vehicle fuel consumption are presented in relation to the reference vehicle model, which is validated against the absolute average fuel consumption of a typical coach, see (Kaiser, 2018).

Figure 10 shows the numerical results of the relative change in fuel consumption $\Delta \mathrm{B}_{\mathrm{S}}$ for the R-744 system with the combination of two-speed pulley gearbox and suction gas interlock depending on the two climatically different driving scenarios. The presented results are
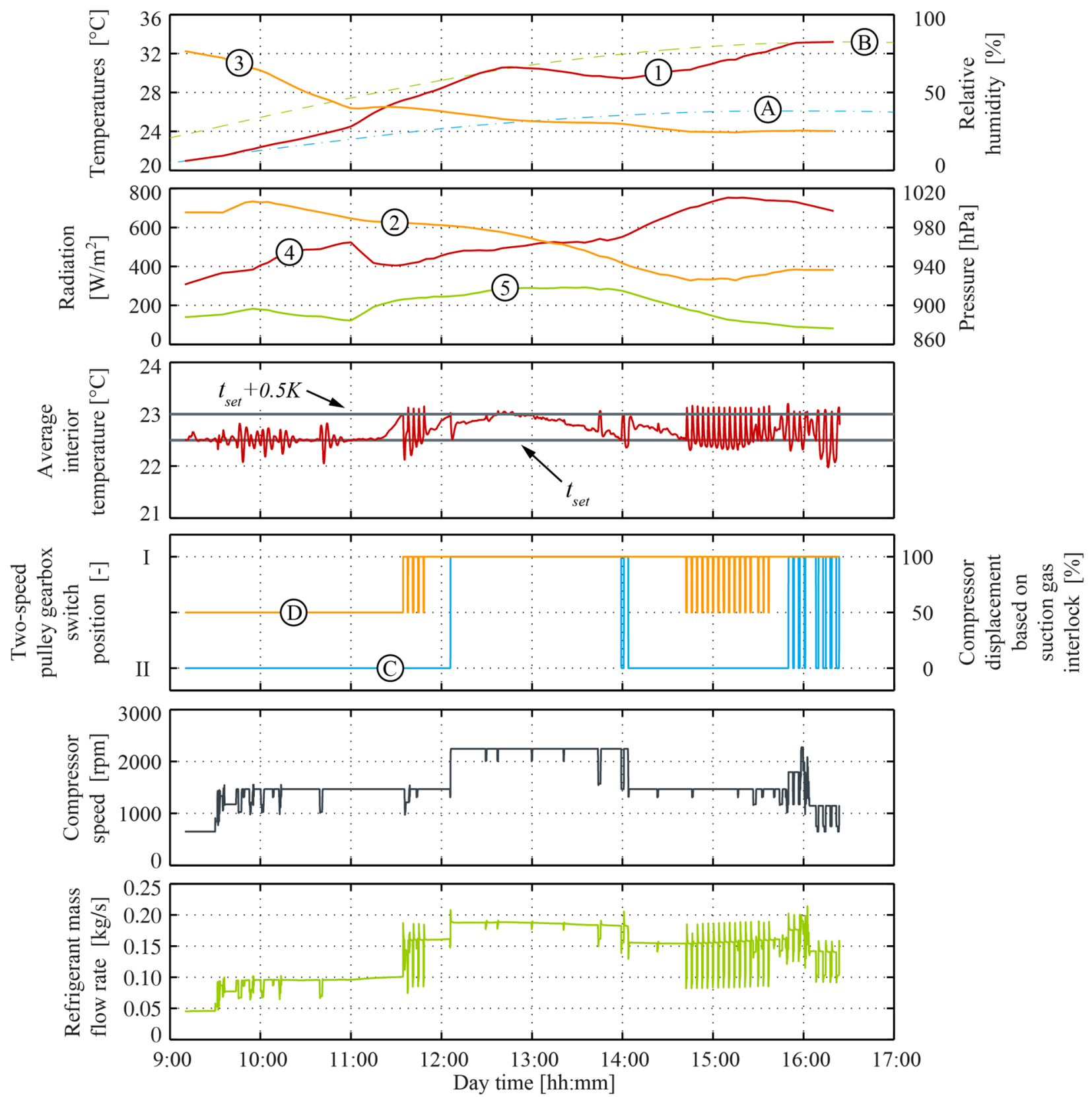

Figure 11. Example results of the total vehicle simulation with refrigerant compressor capacity control by two-speed pulley gearbox and suction gas interlock for virtual driving route scenario Lisbon-Madrid on a representative $15^{\text {th }}$ of August (in accordance with index 8 of virtual driving route scenario). Shows ambient conditions of virtual driving route scenario: (1) ambient air temperature, (2) ambient air pressure, (3) ambient relative humidity as well as (4) direct and (5) diffuse ambient solar radiation; additionally (A) point of departure ambient air temperature, (B) point of destination ambient air temperature. Also shows average interior temperature; (C) control behavior of two-speed pulley gearbox and

(D) suction gas interlock as well as refrigerant compressor speed and compressor outlet refrigerant mass flow rate. 
shown in relation to the reference system simulations with the R-744-based air conditioning systems without the refrigerant compressor capacity control. In addition to the relative change in fuel consumption $\Delta \mathrm{B}_{S}$, the figures show the interior air temperature in the driver's workspace $t_{\text {Driver }}$ as well as the average passenger compartment air temperature $t_{P C}$. Furthermore, the diagrams for the relative change in fuel consumption also include the theoretical limit potential of possible fuel savings achievable by operating the air conditioning system (black boxes). This theoretical limit potential is calculated within an additional reference vehicle simulation in which the use of the air conditioning system does not consume any energy.

The results in Figure 10 show a continuous reduction in fuel consumption. In all these driving scenarios, the cooling capacity produced by the R-744 reference air conditioning exceeds the actual cooling demand. As a result, the compressor capacity control by two-speed pulley gearbox and suction gas interlock reduce the refrigerant compressor capacity as shown in Figure 11. In this manner, the cooling capacity is more closely matched to the actual cooling demand and fuel consumption is reduced. The results in Figure 10 also show that the interior air temperature in the passenger compartment still conforms to the set air temperature of $t_{\text {Set }}=22.5^{\circ} \mathrm{C}$ even when the compressor capacity is adapted by the two-speed pulley gearbox and suction gas interlock. Fuel consumption, and thus the indirect emissions mentioned above through use of the air conditioning system, can be significantly reduced with the presented refrigerant compressor capacity control. The coach's total fuel consumption is reduced by an average of $6.2 \%$ in the Hanover-Munich driving scenario. In the Lisbon-Madrid driving scenario, total fuel consumption is reduced by an average of $5.8 \%$.

The CPU time for integration of the total vehicle simulation model, including the R-744 refrigerant cycle as well as the compressor capacity control by two-speed pulley gearbox and suction gas interlock, was about 2 times faster than the real time. This specific simulated total vehicle model has 830 continuous time states and 28012 time-varying variables. The translated model has 8 linear equations, where the largest linear equation system has size 8 . Further the translated model has 53 nonlinear equations, where the largest nonlinear equation system has size 3 . Model translation and manipulation was done using Dymola.

\section{Conclusion}

The refrigerant cycle in conventional omnibus HVAC systems has a significant influence on fuel consumption and, as a result, on so-called indirect emissions. In addition, direct emissions occur in the refrigerant cycle caused by unintended leakage of refrigerant. To achieve reduced indirect and direct emissions, a natural refrigerant, $\mathrm{CO}_{2}$-based (R-744) air conditioning system with compressor capacity control is a purposeful solution. For this reason a detailed model of an R-744 refrigerant cycle based on the Modelica library (TIL Suite, 2018) was developed and validated. Furthermore, an innovative refrigerant compressor capacity control method based on a combination of speed control by two-speed pulley gearbox and suction gas interlock was presented. To study the R-744-based air conditioning in combination with the presented compressor capacity control, two different realistically modeled driving route scenarios were shown, which were virtually and dynamically driven through using a total vehicle model of a coach. In comparison to an R-744-based omnibus HVAC system, which only reduces unintended direct emissions, the compressor capacity control by combination of two-speed pulley gearbox and suction gas interlock additionally reduces indirect emissions through significant fuel savings. As a result, the coach's total fuel consumption can reduced by an average of $6 \%$ in the considered virtual test driving scenarios.

The presented R-744 refrigerant cycle model has 391 continuous time states and 19740 time-varying variables. The translated model of the R-744 refrigerant cycle has 2 linear equations, where the linear equation system is size 2 and 3. Furthermore, the translated model has 20 nonlinear equations, where each nonlinear equation system has size 1 . The total vehicle simulation model including the R-744 refrigerant cycle as well as the compressor capacity control by two-speed pulley gearbox and suction gas interlock has 830 continuous time states and 28012 time-varying variables. The translated model has 8 linear equations, where the largest linear equation system has size 8 . Furthermore, the translated model has 53 nonlinear equations, where the largest nonlinear equation system has size 3. Model translation and manipulation was done using Dymola.

The CPU time for integration of the standalone R-744 refrigerant cycle model was more than 8 times faster than real time. The CPU time for integration of the total vehicle simulation model, including the R-744 refrigerant cycle as well as the compressor capacity control by two-speed pulley gearbox and suction gas interlock, was about 2 times faster than real time. To determ the CPU time, the R-744 refrigerant cycle model and the total vehicle simulation model were simulated on a standard laptop.

\section{References}

Baehr, H. D., Stephan, K. (2006): Wärme- und Stoffübertragung. Springer Verlag, 2006.

Baumgart, R.; Tenberge, P.; Webner, M.; Gebhardt, J. (2006): Riemenscheibe mit integriertem Getriebe zur Drehzahlregelung des Klimakompressors. Wärmemanagement des Kraftfahrzeuges $V$ : 243-255, Expert-Verlag, 2006. 
Baumgart, R. (2010): Reduzierung des Kraftstoffverbrauches durch Optimierung von Pkw-Klimaanlagen. Doctoral dissertation, Technische Universität Chemnitz, 2010.

Cavallini, A.; del Col, D.; Doretti, L.; Matkovic, M.; Rossetto, L.; Zilio, C. (2006): Condensation in horizontal smooth tubes. A new heat transfer model for heat exchanger design. Heat Transfer Engineering, 27(8): 31-38, Taylor \& Francis, 2006.

Dittus, F. W.; Boelter, L. M. K. (1930): Heat Transfer in Automobile Radiators of the Tubular Type. Publications on Engineering, 2: 443-461, University of California at Berkeley, 1930.

Försterling, S. (2003): Vergleichende Untersuchung von CO2Verdichtern in Hinblick auf den Einsatz in mobilen Anwendungen. Doctoral dissertation, Technische Universität Braunschweig, 2003.

Fujii, T.; Watabe, M. (1987): Laminar Film Condensation in the Subcritical Region - Gravity Controlled Condensation. JSME Trans, 53: 1801-1806, JSEM - Japan Society of Mechanical Engineers, 1987.

Gnielinski, V. (1975): Neue Gleichungen für den Wärme- und den Stoffübergang in turbulent durchströmten Rohren und Kanälen. Forschung im Ingenieurwesen - Engineering Research, 41(1): 8 - 16, Springer-Verlag, 1975.

Gräber, M.; Kosowski, K.; Richter, C.; Tegethoff, W. (2010): Modelling of heat pump with an object-oriented model library for thermodynamic systems. Mathematical and Computer Modelling of Dynamical Systems, 16(3): 195209, Taylor \& Francis, 2010.

Gungor, K. E.; Winterton, R. H. S. (1987): Simplified General Correlation for Saturated Flow Boiling and Comparison of Correlation with Data. Chemical Engineering Research and Design, 65(2): 148-156, Elsevier Science B.V., 1987.

Haaf, S. (1988): Wärmeübertragung in Luftkühlern. Handbuch der Kältetechnik: 6(B), Springer-Verlag, 1988.

Hebeler, M.; Ebeling, P.; Tegethoff, W.; Köhler, J.: Exhaust Waste Heat Recovery for Intercity Bus Climatisation using Rankine Technology with Focus on Topology Design. $2^{\text {nd }}$ ETA Conference, IAV Automotive Engineering, 2018.

Kaiser, C., Baumgart, R., Aurich, J., Tegethoff, W., Köhler, J. (2013): Konzepte für die Reduzierung des Kraftstoffverbrauchs von Omnibusklimaanlagen. 12. Internationale Fachtagung Nutzfahrzeuge: 269-284, VDIVerlag, 2013.

Kaiser, C. (2018): Untersuchungen zur Effizienz- und Leistungsverbesserung von Omnibusklimaanlagen. Unpublished doctoral dissertation, Technische Universität Braunschweig, 2018.

Kondou, C.; Hrnjak, P. (2011): Heat Rejection from R744 Flow Under Uniform Temperature Cooling in a Horizontal Smooth Tube around the Critical Point. International Journal of Refrigeration, 34: 1293- 301, Elsevier Science B.V., 2011.

McAdams, W. H.; Woods, W. K.; Heroman, L. C. (1942): Vaporization inside horizontal tubes-II-benzene-oil mixtures. Trans. ASME, 64(3): 193-200, American Society of Mechanical Engineers, 1942.

Meise, S.; Kaiser, C.; Engel, P.; Lemke, N.; Köhler, J.: R-744Ejektor-Wärmepumpe für elektrische Gelenkbusse. Deutsche Kälte-Klima-Tagung, DKV e.V., 2018.
METEONORM (2016): Software for the determination of worldwide weather data. METEOTEST, Version: 7.1.10 [Computer Software], 2016.

Remund, J.; Müller, S.; Kunz, S.; Huguenin-Landl, B.; Schmid, C.; Schilter, C. (2013): METEONORM - Global Meterological Database. Hanbook I/II. METEOTEST, 2013.

Richter, C. C. (2008): Proposal of New Object-Oriented Equation-Based Model Libraries for Thermodynamic Systems. Doctoral dissertation, Technische Universität Braunschweig, 2008.

Rohsenow, M. W.; Hartnett, P. J.; Ganic, E. N. (1985): Handbook of Heat Transfer Fundamentals. McGraw-Hill, 1985.

Schulze, C. W. (2013): A Contribution to Numerically Efficient Modelling of Thermodynamic Systems. Doctoral dissertation, Technische Universität Braunschweig, 2013.

Swamee, P. K.; Jain, A. K. (1976): Explicit Equations for Pipe-Flow Problems. Journal of the Hydralics Division: 102(5): 657-664, ASCE - American Society of Civil Engineers, 1976.

Tegethoff, W.; Schulze, C.; Gräber, M.; Huhn, M.; Stulgies, N.; Kaiser, C.; Loeffler, M. (2011): TEMO: Thermische echtzeitfähige Modelle. Bundesministerium für Bildung und Forschung (BMBF), 2011.

TIL Suite (2018): Software package for the simulation of thermal systems. TLK-Thermo GmbH, Version 3.4 [Computer Software], 2018.

Wallis, G. B. (1969): One-dimensional Two-phase Flow. MCGraw-Hill, 1969.

\section{Nomenclature}

$\begin{array}{llc}N u & \text { Nusselt number } & (-) \\ R e & \text { Reynolds number } & (-) \\ \eta & \text { Efficiency } & (-) \\ \lambda & \text { Volumetric efficiency } & (-) \\ \zeta & \text { Pressure loss coefficient } & (-) \\ h & \text { Specific enthalpy } & (\mathrm{J} / \mathrm{kg}) \\ i & \text { Transmission ratio } & (-) \\ \dot{m} & \text { Mass flow rate } & (\mathrm{kg} / \mathrm{s}) \\ M & \text { Torque } & (\mathrm{Nm}) \\ n & \text { Speed } & \left(\mathrm{s}^{-1}\right) \\ t_{a m b} & \text { Ambient air temperature } & \left({ }^{\circ} \mathrm{C}\right) \\ t_{S e t} & \text { Set value of interior air temperature } & \left({ }^{\circ} \mathrm{C}\right) \\ t_{D r i v e r} & \text { Air temperature in driver's workspace } & \left({ }^{\circ} \mathrm{C}\right) \\ t_{P C} & \text { Air temperature in passenger compartment } & \left({ }^{\circ} \mathrm{C}\right) \\ \Delta B_{S} & \text { Relative difference in fuel consumption } & (\%) \\ I H X & \text { Internal heat exchanger } & - \\ V_{H} & \text { Displacement volume } & \left(\mathrm{m}^{3}\right) \\ V L E & \text { Vapor-liquid equilibrium } & - \\ z & \text { Number of cylinders } & (-)\end{array}$

